\title{
Vantagem competitiva e o uso das tecnologias de informação e comunicação: estudo na cadeia produtiva do vinho do Rio Grande do Sul
}

\author{
Competitive advantage and the use of information technology and \\ communication: studies in the production chain wine of Rio Grande do Sul
}

\author{
Rafael Alfonso Brinkhues ${ }^{[a]}$, Maria Alexandra Viegas Cortez da Cunha ${ }^{[b]}$
}

[a] Mestre em Administração pelo Programa de Pós-Graduação em Administração da Pontifícia Universidade Católica do Paraná (PUCPR), professor do Instituto Federal de Educação, Ciência e Tecnologia de Santa Catarina, Gaspar, SC - Brasil, e-mail: rafabrink@gmail.com

[b] Doutora em Administração pela Universidade de São Paulo, professora da Pontifícia Universidade Católica do Paraná (PUCPR), Curitiba, PR - Brasil, e-mail: alexandra.cunha@pucpr.br

\section{Resumo}

A indústria vinícola nacional passa por dificuldades, em especial a do Estado do Rio Grande do Sul, que concentra $90 \%$ da produção do País. Entre essas dificuldades, estão a perda de parcela do mercado interno, a falta de reconhecimento das marcas brasileiras nos mercados interno e externo e a falta de estrutura organizacional para enfrentar a concorrência acirrada de outros países, como Argentina, Chile e Uruguai. As tecnologias de informação e comunicação (TICs) são fontes de vantagem competitiva ou podem potencializar as vantagens competitivas de uma indústria. Esta pesquisa tem o intuito investigativo de compreender como a adoção de TICs nas estruturas organizacionais, e nos processos de negócios das vinícolas do Estado do Rio Grande do Sul, podem apoiar vantagens competitivas para garantir sua competitividade e sobrevivência no mercado. Este estudo busca - apoiado em referencial teórico, com pesquisa bibliográfica sobre o setor, entrevistas com especialistas e questionários preenchidos por vinícolas - descrever a indústria e compreender a possibilidade de as TICs colaborarem no sentido de reforçar as vantagens competitivas existentes ou futuras. Para alcançar tais objetivos, além de descrever a indústria, analisar-se-á, também, o atual nível de utilização das TICs pelas empresas do setor, a percepção do potencial de utilização das TICs pelos gestores e a percepção desse potencial para o aumento da competitividade com o produto externo, seja na concorrência pelo mercado interno ou externo. As conclusões do trabalho mostram um potencial para o desenvolvimento das TICs no 
suporte e a potencialização das vantagens competitivas da indústria do vinho, mas não se encontrou, nesta pesquisa, a utilização dessa ferramenta com tal finalidade.

Palavras-chave: Tecnologias da informação e comunicação. Vantagens competitivas. Cadeia produtora vinícola. Estratégias em vinícolas. Rastreabilidade.

\begin{abstract}
The domestic wine industry is going through some difficulties, in particular that of the State of Rio Grande do Sul, which responds for ninety percent of the production of the country. Among them, the loss of the domestic market share, the lack of awareness about Brazilian brands in the domestic and external market and the lack of organizational structure to face the tight competition from other countries, such as Argentina, Chile and Uruguay. The information and communication technologies (ICTs) constitute the source for competitive advantage or may potentiate the competitive advantages of an industry. This paper has the investigative purpose of understanding how the adoption of ICTs in the organization structures and business processes of wine industries in the State of Rio Grande do Sul may support competitive advantages in order to assure their competitiveness and survival in the market. This study seeks, with the support of theoretical reference material, with bibliographic research on the sector, interviews with experts and questionnaires filled by wine industries, to describe the industry and understand the possibility of ICTs to cooperate towards the strengthening the existing or future competitive advantages. In order to reach such goals, besides describing the industry, the current level of use of ICTs by the companies of the sector, the perception of the potential for use of ICTs by the managers and the perception of such potential for the increase of competitiveness with the external product, either in the competition for the internal or external market, will also be analyzed. The conclusions of this paper present some potential for the development of ICTs in the support and potentiation of competitive advantages in the wine industries, however, in this paper, the use of such tool for that purpose was not verified.
\end{abstract}

Keywords: Information and communication technologies. Competitiveadvantages. Wine producing chain. Strategies in wine industries. Traceability.

\section{Introdução}

Ocultivo de uva no Brasil data das primeiras décadas do século XVI, logo após a descoberta do País pelos portugueses. Hoje, a vitivinicultura está presente em dez estados federativos do Brasil, existem 1.200 vinícolas, com produção de mais de 350 milhões de litros de vinho por ano. Desse volume, $90 \%$ é produzido no Rio Grande do Sul. A atividade movimenta a economia de 20 mil famílias gaúchas (COPETTI, 2008). Em 2009, foram produzidos 433 milhões de litros de vinho no Brasil, uma redução de $16,8 \%$ em relação ao mesmo período de 2009 , reflexo da crise no setor nacional, combinada com uma safra deficitária de uva (IBRAVIN, 2010).

O Estado do Rio Grande do Sul vem buscando inúmeras estratégias para driblar o grave problema da queda nas vendas da produção. A concorrência com o produto importado, que já representava mais de $70 \%$ do consumo interno desse segmento, ganhou força com a desvalorização cambial do dólar ocorrida nos últimos anos. Do mercado interno, a ameaça veio de produtos substitutos, coquetéis e falsas sangrias. Esses produtos têm custo baixíssimo, por serem feitos apenas de álcool, corante e aromatizante, chegando ao mercado por $\mathrm{R} \$ 1,60$ a garrafa (COPETTI, 2008).

Os órgãos do setor indicam cinco estratégias para ajudar a indústria a sair dessa crise: inflar o consumo interno, aumentar a exportação, investir em espumantes, incrementar a qualidade e criar uma identidade e marca forte. Nenhuma das estratégias está ligada (COPETTTI, 2008) explicitamente à utilização das tecnologias da informação e comunicação (TICs), mas, partindo do pressuposto que elas oferecem diversas possibilidades de uso e têm demonstrado o potencial para o surgimento de vantagem competitiva, justifica-se o tema deste trabalho: a vantagem competitiva e a utilização das TICs na 
cadeia produtiva do vinho no Estado do Rio Grande do Sul.

Esta pesquisa buscou identificar, na cadeia produtiva do vinho no Estado do Rio Grande do Sul, uma relação entre a utilização das TICs e a vantagem competitiva dessa cadeia. O estudo foi realizado com base em pesquisa bibliográfica, entrevistas com especialistas e questionários enviados às vinícolas do Estado. Ao longo deste estudo exploratório e descritivo, foram analisados e apresentados dados sobre a indústria vinícola do Rio Grande do Sul, o nível de utilização de TICs atual, a percepção dos produtores sobre o potencial de utilização das TICs, a utilização das TICs na concorrência com os produtos importados e para a exportação, além de se buscar identificar vantagem competitiva relacionada às TICs na indústria. Buscou-se responder, com esta pesquisa, o seguinte problema: como a utilização das TICs, na cadeia produtiva do vinho, pode suportar ou ampliar a vantagem competitiva?

Neste estudo, a variável independente será definida como a utilização das TICs, enquanto a variável dependente será a criação ou ampliação de vantagem competitiva sustentável(CRESWEL, 1994, p. 59). Para se atingir esse objetivo, foram realizadas as seguintes etapas: a descrição da indústria do vinho no Rio Grande do Sul; verificação do nível de utilização atual das TICs na cadeia produtiva do vinho, desde a produção até a venda ao consumidor final; averiguação da percepção dos produtores de vinho quanto à possível agregação de valor do uso das TICs na cadeia do vinho; verificação de como o uso das TICs pode diferenciar uma empresa das demais e a produção nacional da produção dos demais países; e identificação de vantagem competitiva gerada ou potencializada pela utilização das TICs na indústria do vinho gaúcho.

\section{Estratégia, tecnologia da informação e comunicação e TICs como vantagem competitiva}

$\mathrm{Na}$ revisão de literatura para este trabalho, foram descritas diferentes abordagens sobre vantagem competitiva e, também, algumas implicações relacionadas ao advento das TICS nas organizações. Por fim, foi apresentado o que se escreveu sobre TICs como fontes ou apoiadoras de vantagem competitiva.

\section{Estratégia}

Para se definir vantagem competitiva é importante retomar alguns pontos do campo de estudo da estratégia. Não existe consenso sobre o conceito de estratégia. Porter (1989) define estratégia como um posicionamento favorável, único e valioso da empresa dentro de uma indústria ou setor de negócios. Ampliando os conceitos, Mintzberg (2001) aponta que a estratégia é definida de cinco maneiras diferentes, dependendo da abordagem feita pelos estudiosos: como um plano, explicitando de maneira formal o processo de formulação da estratégia; como um truque, ou seja, uma ação para provocar alterações desejadas nos rumos da concorrência; um padrão de existência das ações das organizações, que podem ser planejadas ou não; uma posição ocupada pela organização em um ambiente diante das demais organizações, conforme a definição, exposta anteriormente, de Porter; e como uma perspectiva, concebida na mente dos estrategistas ou assimilada de maneira coletiva pela organização.

Além disso, Mintzberg, Ahlstrand e Lampel (2000) realizaram uma caracterização de dez escolas da estratégia. Cada escola enfoca a formação e/ou o processo estratégico de maneira diferente. Separadas em dois grupos, as escolas prescritivas apresentam como a estratégia deve ser formulada e realizada, enquanto as escolas descritivas buscam apresentar explicações acerca da maneira como as estratégias são formuladas e conduzidas.

\section{Organização industrial}

A abordagem da escola da organização industrial tem origem nas Ciências Econômicas. Porter (1980) afirma que o desempenho de uma empresa é dado pela atratividade da indústria (mediante junção das suas cinco forças) e do posicionamento da organização nesse setor industrial. Considerando que todas as empresas da mesma indústria acabam por possuir os mesmos recursos, competências e capacidades, a diferenciação só ocorre pelo posicionamento nesse setor industrial. $\mathrm{O}$ foco está no ambiente externo e a estrutura da indústria é fundamental na decisão estratégica. Contudo, se empresas da mesma indústria apresentam desempenhos diferentes, é porque as que se diferenciam utilizam fontes de vantagem competitiva (PORTER, 1989). 
A abordagem da análise da organização industrial, então, está focada nos mercados, na competição e na consciência do posicionamento das organizações em sua indústria como elementos fundamentais no processo estratégico (PORTER, 1980). Porter (1980) ainda indica que os elementos básicos para a definição dessa posição da organização dentro da indústria estão nas cinco forças (concorrência existente, ameaça de novos entrantes, ameaça de produtos substitutos, poder de barganha dos fornecedores e poder de barganha dos consumidores) e na matriz $2 \times 2$ (que cruza os dados sobre os objetivos de mercado e as estratégias genéricas) em que se definem as estratégias competitivas.

\section{A visão baseada em recursos}

Contrapondo o conceito da abordagem anterior, a visão baseada em recursos pressupõe a heterogeneidade nos recursos das organizações. Isso porque os recursos são acumulados ao longo do tempo em que são desenvolvidos para que se transformem em uma vantagem competitiva (PETERAF, 1993). Dentre os recursos das organizações estão as capacidades organizacionais, que são as habilidades específicas da organização. Elas são manifestadas nos processos em combinações complexas de recursos tangíveis e intangíveis. São específicas da empresa, características da organização e intransferíveis (MAKADOK; AMIT; SHOEMAKER apud MORGAN, 2006). Ou seja, não são os recursos em si, mas a maneira como são utilizados e a combinação entre eles, que geram serviços e produtos diferenciados.

Barney (1991), além do pressuposto da heterogeneidade, pressupõe a imobilidade dos recursos. O referido autor condiciona a esses dois pressupostos a criação de uma vantagem competitiva sustentável. Para ele, recursos incluem todos os ativos, capacidades, processos organizacionais, atributos da firma e conhecimento, controlados pela firma, que possibilitam conceber e criar estratégias que melhoram sua eficiência e eficácia, pois recursos da firma são forças.

A vantagem competitiva é dada quando uma firma implementa uma estratégia de criação de valor que nenhum outro competidor faz ao mesmo tempo. Se as outras firmas não podem copiar os benefícios dessa estratégia, então se tem uma vantagem competitiva sustentável. Entretanto, isso não significa que essa vantagem durará para sempre, pois alterações estruturais na indústria podem acontecer e reorganizar o que são recursos relevantes (BARNEY, 1991). Barney ainda define quatro atributos para que um recurso tenha um potencial para gerar vantagem competitiva sustentável. O recurso deve ser valioso, raro, insubstituível e imperfeitamente imitável.

\section{Tecnologia da informação e comunicação}

Segundo Castells (1999), as TICs, em duas décadas, se expandiram de modo que conectaram todo o mundo. Contudo, o autor alerta para o fato de existirem ainda grandes áreas geográficas e segmentos da população desconectados desse novo sistema. Desde a década de 1980, os computadores não podem mais ser concebidos isoladamente, mas em um sistema compartilhado e interativo de computadores em rede. Ele diz que essas mudanças foram além do sistema de tecnologia e ressalta que também suas interações sociais e organizacionais sofreram mudanças. Também há a preocupação com a aplicação dos recursos da tecnologia da informação. Mesmo atribuindo a emergência de um novo sistema tecnológico, nos anos 1970, à dinâmica autônoma da descoberta e difusão tecnológica, Castells (1999) admite que a Revolução da Tecnologia dependeu histórica, cultural e especialmente de algumas circunstâncias específicas, que determinaram sua evolução. Quanto à importância da tecnologia da informação, Castells afirma que "a revolução da tecnologia da informação foi essencial para a implementação de um importante processo de reestruturação do sistema capitalista a partir da década de 80".

Webster (1995) conclui que há, sim, uma explosão de informações, mas é prematuro conceber a existência de uma sociedade da informação. Ele prefere indicar a existência de uma "informatização" das relações estabelecidas. As constatações quantitativas devem ser aliadas a explorações qualitativas, sobre os efeitos das novas tecnologias na ordem social.

\section{TICs como vantagem competitiva}

Porter (1999) descreve a importância da informação como vantagem competitiva. Para Cavalari e Cunha (2008, p. 36),

a informação exerce papel fundamental na tomada de decisões pelos executivos das organizações. 
As empresas que possuem maior quantidade possível e acesso mais rápido à informação, de boa qualidade, podem definir mudanças em seu direcionamento à frente de seus concorrentes ao encontro de novas oportunidades.

Para Porter (2001), existem três aspectos essenciais afetados pela revolução gerada pela tecnologia da informação: a alteração das regras de competição, como consequência da mudança da estrutura setorial; a criação de formas de superar o desempenho da concorrência, gerando vantagem competitiva; e a disseminação de novos negócios a partir dos já existentes.

A TIC é vista como fonte de criação de negócios, de novas formas de relacionamento entre empresas e com o consumidor. A TIC também pode ser vista como um fator que viabiliza a integração em escala mundial, que estende a competição de mercado a uma nova dimensão (CARVALHO; LAURINDO, 2003).

Ao analisar as TICs, como fonte de vantagem competitiva, descobre-se uma visão contrária a essa idéia: os argumentos de Carr (2003), que considera as TICs como uma commodity. A principal base de comparação utilizada por esse autor é que as TICs seriam como as redes de energia elétrica, que estão disponíveis a todos, com preços acessíveis, e por isso não podem ser fonte de vantagem competitiva sustentável. Trata-se de uma infraestrutura, como outras que já foram desenvolvidas historicamente energia, ferrovias. $\mathrm{O}$ autor cita, ainda, que um insigth sobre o uso de uma tecnologia pode criar uma vantagem competitiva, que pode ser sustentada por um tempo até que seja copiada por outras empresas. No caso da tecnologia da informação, essa diferenciação seria muito breve, graças à velocidade no trânsito das informações. Apesar do risco de um investimento desnecessário, o autor também cita que uma vantagem em TICs adquirida, mesmo que depois propagada em diversas empresas, pode se tornar uma vantagem de posicionamento duradouro.

Weill e Ross (2006) apontam cinco decisões críticas de TICs para tornar-se um ativo estratégico. Primeiro, os serviços de TICs precisam ser coordenados de maneira centralizada e compartilhada, e as decisões sobre os princípios de TICs devem ser declarações de alto nível sobre como as TICs são utilizadas no negócio. A segunda, a arquitetura de TICs deve ser definida a partir de um conjunto de políticas, relacionamentos e opções técnicas adotados para obter a padronização e a integração das técnicas e de negócio desejados. A terceira, sobre as decisões de infraestrutura de TI. Os autores defendem que os componentes técnicos são commodities, porém, o diferencial é a conversão desses componentes em serviços comuns úteis, por meio de uma infraestrutura humana de TI. Os autores citam que a quarta decisão crítica de TICs está ligada às necessidades de aplicação nos negócios e costuma ter dois objetivos conflitantes, a criatividade e a disciplina. E, por último, a tomada de decisões sobre o investimento em TICs deve se diferenciar dos demais processos decisórios, pela rapidez com que as mudanças ocorrem.

Maçada e Becker (1998, p. 8) criaram um modelo para observar criticamente o impacto das TICs nas variáveis estratégicas e seu alinhamento com os negócios. Eles concluíram que, com o instrumento que utilizaram,

uma organização pode determinar se as TICs podem ser utilizadas para obtenção de vantagem competitiva. Outra aplicação prática é avaliar se seus executivos são capazes de perceber os efeitos das TICs e suas relações com as estratégias da organização.

Em uma adaptação das cinco forças competitivas de Porter (1979), Balarine (2002, p. 5) coloca as forças concorrentes sob efeitos das TICs e da internet: como os novos entrantes utilizam as novas TICs, como as TICs afetam a cadeia de suprimentos, como os atuais concorrentes estão explorando as TICs e a internet, o que os clientes esperam dessas tecnologias e que produtos substitutos podem surgir com a utilização das novas tecnologias. Para o autor "o modelo de análise [...] representa um caminho sensato para a empresa se posicionar, partindo do conhecimento dos efeitos das tecnologias da informação e da Internet sobre sua indústria”.

A convergência digital impulsionada pela revolução tecnológica oferece a oportunidade para melhorar a competitividade da economia brasileira, aumentando a produtividade das pessoas e das empresas (KNIGHT; FERNANDES, 2006). A insensibilidade dos países desenvolvidos, diante dos em desenvolvimento, deverá ser enfrentada com o avanço da TI, do conhecimento e do profissionalismo, em busca de uma ordem mundial adequada aos problemas globais (LEVY, 1993). 
A tecnologia da informação pode afetar diretamente a gestão dos negócios agroindustriais. Ao facilitar a busca, o acesso, o armazenamento e a disseminação de informações, as TICs deverão cada vez mais servir como instrumento de comunicação e coordenação entre os agentes de um sistema agroindustrial (VILLELA, 2003).

Para tanto, uma das propostas do projeto e-Brasil (KNIGHT; FERNANDES; CUNHA, 2007), em relação ao comércio eletrônico brasileiro, é fortalecer a infraestrutura de comunicação fora dos recintos urbanos, para que o agronegócio e a economia rural sustentada por pequenas empresas possam usufruir da inovação.

\section{Contexto: a indústria do vinho no Rio Grande do Sul e as fontes de vantagem competitiva na cadeia vinícola}

As vantagens que diferenciam um vinho estão muito ligadas às características dos produtos. Essas características são fortemente influenciadas pela posição geográfica da região produtora. No Brasil, o Estado que reúne essas características é o Rio Grande do Sul, motivo pelo qual esse Estado concentra a maior produção nacional. Afirma Triches (2007) que se observa de forma crescente prêmios internacionais serem concedidos às vinícolas gaúchas. Contudo, o autor acredita que não basta só explorar os diferenciais locais para gerar vantagem interna e externa, mas buscar alternativas para enfrentar a concorrência do produto externo.

Alguns fatores começaram recentemente a alterar o cenário de costumes e tradição, alterando o consumo do produto no País, destacando-se:

- descoberta de benefícios à saúde: benefícios comprovados do consumo regular de vinho tinto para a saúde humana;

- ampliação dos canais de distribuição de vinhos (principalmente os finos) e espumantes: apesar de esse ser um gargalo muito importante da cadeia gaúcha, percebe-se o início de um processo de melhoria nos últimos anos; aumento da promoção da imagem dos produtos no País: ampliação das ações de marketing e propaganda por parte de vinícolas, organizações e outros segmentos interessados;
- desenvolvimento do enoturismo: atividade econômica que proporciona novas possibilidades de geração de renda, aliada ao desenvolvimento turístico, especialmente nas regiões produtoras de vinhos e espumantes.

Triches (2007) aborda a estratégia da indústria vinícola gaúcha, dada a grande concorrência internacional advinda, em grande parte, dos vizinhos do Mercosul - os empresários vinícolas da Argentina e do Chile, principalmente. Dessa forma, o autor diz que os gaúchos buscaram intensificar suas estratégias empresariais, tanto defensivamente como buscando a abertura de novos mercados. Essas estratégias variaram dependendo do tamanho e das características de cada empresa (tamanho, produtos, etc.). O resultado do estudo mostrou uma carência de estrutura profissional, causa atribuída pelo autor à escolha de estratégias, muitas vezes irracionais, à exceção de empresas maiores e algumas micro e pequenas vinícolas. A seguir, listaremos as estratégias encontradas pelo autor:

a) estratégias de preço e custo: relacionadas a vinhos comuns e que independem do tamanho da vinícola;

b) estratégias de segmentação: percebidas apenas em grandes vinícolas, como, por exemplo, produtos destinados a adolescentes, a mulheres, à crescente demanda de consumidores de vinhos em busca de melhoria na saúde e produtos ecológicos;

c) estratégias de diferenciação: mais relacionadas aos vinhos finos, observadas tanto em grandes e médias vinícolas quanto em vinícolas pequenas com produção limitada, primando pela qualidade;

d) estratégias de inovação: são as menos representativas, dentre elas, estão novos formatos de armazenamento e diferentes embalagens;

e) estratégias de diversificação: começaram a ter relevância nos últimos anos, principalmente pela abertura do leque de opções de produtos;

f) estratégias de mercado externo: o maior esforço nesse sentido foi a criação do consórcio Wines from Brazil, que iniciou as atividades em 2002 e abrange 14 das 20 maiores 
vinícolas da região; na segunda metade da década, surgiram novos mercados consumidores do vinho brasileiro, como Suriname, Estônia, Inglaterra e Emirados Árabes Unidos, entre outros; dentre os fatores que mais influenciam o sucesso da estratégia de mercado externo está a indicação geográfica do Vale dos Vinhedos, ocorrida em fevereiro de 2007;

g) estratégias integradas: a associação de produtores de vinhos de regiões específicas, como é o caso da Associação dos Produtores de Vinho do Vale dos Vinhedos (Aprovale), que conquistou o certificado de indicação de procedência intitulado "Vale dos Vinhedos", demarcação geográfica dos vinhos produzidos com uvas e em vinícolas daquela região do Estado, situada na serra, no município de Bento Gonçalves.

Outra autora também abordou a cadeia produtiva de vinhos no Estado do Rio Grande do Sul. Teruchkin (2003) acredita que os principais fatores que diferenciam um vinho são: o modo como ele é produzido; conter uma matéria-prima de melhor qualidade; ser mais envelhecido que os outros; ter uma relação preço/qualidade muito boa ou uma identidade própria da vinícola bastante consolidada. Ela divide o estudo do segmento de vinhos finos em três análises. Primeiramente, as características dos vinhos; depois, uma análise do desenvolvimento histórico; e, por último, aborda a situação do mercado nacional à época do seu estudo.

A autora comenta que são muito importantes, nas características dos vinhos, os fatores tradicionais, ou seja, as técnicas e ensinamentos transmitidos de geração em geração, que devem ser considerados. Outro ponto de relevância nas características do produto se refere à sua armazenagem, principalmente para algumas variedades que necessitam de envelhecimento em barricas de carvalho e também de algum tempo em repouso na adega antes da comercialização (TERUCHKIN, 2003).

A partir da década de 1990, o consumo se manteve praticamente estável nos países que são considerados grandes consumidores de vinho. No entanto, novos e importantes exportadores entraram no mercado internacional de vinhos, ao desenvolverem diferentes variedades, tecnologias de produção e o marketing. Houve redução no preço médio dos vinhos e aumento da demanda, em função das recomendações médicas do uso terapêutico do vinho. $\mathrm{Na}$ América Latina, os principais produtores são: Chile, seguido de Argentina e depois Brasil e, com menor importância, outros países, como Uruguai, Bolívia e Paraguai. No que se refere à distribuição, houve grande incremento de vendas de vinhos nas redes de supermercados, o que, de certa forma, pode ter sido prejudicial às empresas produtoras de vinho, pelo grande poder de negociação das grandes redes de supermercados e hipermercados, que forçaram a redução da margem de lucro das vinícolas. Foi ainda destacado o reflexo da indústria em outros segmentos, principalmente inter-relacionados com a agricultura, desde as pequenas propriedades familiares produtoras de vinho (predominante na região) até as indústrias de máquinas e insumos agrícolas. No mercado interno, dá-se destaque para o aumento do consumo brasileiro, acompanhado do aumento nas importações de vinhos a partir das reduções das alíquotas de importação ocorridas em meados da década de 1990 (TERUCHKIN, 2003). Entretanto, com a utilização de novas estratégias, a indústria local tem buscado reverter a queda, nas já pequenas exportações, apresentada a partir desse período.

\section{Método}

Este estudo é de objetivo exploratório e descritivo, aproximando-se do fenômeno para melhor compreendê-lo e tendo o objetivo de caracterizá-lo. A análise qualitativa, de corte vertical, foi realizada sem controle de variáveis. Para realizar o levantamento foram utilizadas diferentes técnicas de pesquisa, com a adoção de três instrumentos de coleta: pesquisa bibliográfica, entrevistas individuais semiestruturadas e aplicação de questionários. Por meio desses três instrumentos de pesquisa, buscou-se responder às perguntas-guia:

- Como está organizada a indústria vinícola do Rio Grande do Sul?

- Qual a utilização das TICs na indústria vinícola do RS?

- Qual a percepção dos produtores de vinho quanto ao potencial de utilização das TICs? 
- Como o uso das TICs pode diferenciar uma empresa das demais, no caso da indústria vinícola?

- Como a utilização das TICs na indústria do vinho pode gerar ou ampliar vantagem competitiva?

O Rio Grande do Sul concentra mais de 90\% da produção vinícola do Brasil. Esse Estado possui quatro regiões produtoras: a Campanha, os Campos de Cima da Serra, a Serra do Sudeste e a Serra Gaúcha. Essa última se destaca das demais pelo volume e qualidade apresentados e é composta por 310 vinícolas. Pela representatividade da produção e da exportação no cenário nacional, foi escolhida essa região como população abordada na pesquisa.

Na primeira etapa da pesquisa foram feitas entrevistas semiestruturadas com duas vinícolas da região e com duas entidades associativas da cadeia produtiva. Essas entrevistas, além da revisão de literatura, serviram de base para a elaboração do questionário, que questionário foi enviado por correio eletrônico às vinícolas da região. Como nem todas possuíam esse meio de comunicação, o questionário foi enviado para 130 vinícolas. A amostragem intencional, por conveniência, foram os questionários que retornaram respondidos. Foi obtido o retorno de $9,2 \%$ desses questionários, em um total de doze, tendo sido um deles desconsiderado por insuficiência de informações. Sobre os questionários foi desenvolvido um trabalho de proporção, visto que o pequeno número de casos não permitiu métodos de análise mais sofisticados.

\section{Apresentação e análise dos resultados}

A partir das entrevistas, complementadas pela revisão do contexto do setor, chega-se aos principais desafios impostos ao setor vinícola gaúcho: a competição, com a entrada do produto importado no país, a partir da década de 1990; o desconhecimento do produto nacional no mercado interno; e a necessidade do aprimoramento da qualidade da matéria-prima.

\section{A competição com os produtos importados}

O potencial de crescimento do consumo per capita no Brasil (comparando com o consumo de países vizinhos - Argentina, Uruguai e Chile) atraiu exportadores de vários lugares para o Brasil. Ocorre que esses exportadores não desenvolvem nenhuma estratégia para aumento do consumo interno, o qual, apesar de existir, ocorre em ritmo menor que o volume importado, verificando-se, então, uma tomada do mercado nacional pelo vinho estrangeiro.

Um desafio grave para a indústria brasileira é o fato de o vinho nacional não ter competitividade de custos, tornando-se, muitas vezes, mais caro do que os vinhos importados da mesma categoria. Essa vantagem competitiva de custos dos vinhos finos, principalmente da Argentina e do Chile (que detêm mais de 50\% do mercado de vinhos finos do Brasil), deve-se à produção em escala maior pelas vinícolas desses países, além de maior experiência na sua produção e comercialização.

\section{Investimentos em qualidade das matérias-primas}

Existe uma qualidade mínima necessária da uva, para a elaboração de vinhos pela indústria, qualidade que alguns produtores ainda não conseguiram atingir. A busca pela qualidade é um reflexo da exigência do consumidor por um produto cada vez melhor, o que forçou as empresas a investirem em tecnologia. Ocorre que o aprimoramento do produto final, via melhoria na tecnologia de produção, chegou ao seu limite, sendo imprescindível que haja uma melhoria na qualidade da matéria-prima, para que se atenda o padrão exigido pelo mercado consumidor. Foi referido, ainda, que a produção de boas uvas passa por um longo trabalho de investimento de médio prazo, o que não pode ser atingido em um ano. Deve haver investimento durante todo o processo de produção da uva, e não exclusivamente com a substituição de mudas de variedades, mas, principalmente, com a inclusão de tecnologia.

\section{Desafios do mercado externo}

Se há desconhecimento do produto nacional no mercado brasileiro, também o vinho produzido no Rio Grande do Sul ainda é muito desconhecido externamente. O principal desafio da indústria para aumentar o volume de exportações, portanto, é tornar o vinho nacional conhecido no mercado externo. O enfrentamento desse problema é uma das atribuições 
atuais do Instituto Brasileiro do Vinho (Ibravin), que desde 2008 vem trabalhando a marca coletiva Vinhos do Brasil no mercado interno; e a marca Wines From Brazil no mercado externo. A estratégia é trabalhar principalmente o posicionamento dessa marca, destacando seus atributos, especialmente por meio de mídia. A ideia não é trabalhar com os atributos qualitativos do produto, mas com o conceito de sensações no consumidor. Pela implementação dessas ações, buscando o resultado, em médio prazo, de reposicionar o produto nacionalmente e de consolidar a marca internacionalmente, onde praticamente é desconhecida.

\section{O vinho gaúcho e a estratégia para o espumante}

Especificamente sobre os produtos produzidos na serra gaúcha, há um crescente reconhecimento da qualidade dos espumantes, que já reflete no aumento do consumo. Estudos demonstram que a qualidade dos espumantes é superior à dos vinhos finos da região. Há uma vantagem para o produto nacional diante dos demais do Mercosul: a uva é mais ácida e menos madura, suportando, assim, a segunda fermentação necessária. Há um reconhecimento de que pouco se é feito para explorar essa vantagem aparentemente reconhecida do produto brasileiro, investimento mais notado especificamente em algumas empresas. Outra bebida, cuja produção poderia ter mais investimento para explorar esse potencial local, seria o frisante, com a adição de gás.

O espumante pode ser uma "porta de entrada" para o mercado externo, uma vez que o número de países fornecedores de espumantes para esses grandes mercados consumidores é bem menor do que o número de países fornecedores de vinhos finos. Ou seja, a estratégia seria utilizar o espumante de maior qualidade para abrir mercado para os vinhos finos nacionais, uma vez que, atualmente, os espumantes representam menos de $5 \%$ do volume da produção vinícola nacional.

\section{Desafios e estratégias da cadeia produtiva do vinho gaúcho}

Existe um projeto em andamento, objetivando a interligação dos elos da cadeia produtiva. Tal projeto tem previsão legal e está sendo desenvolvido pelo Ministério da Agricultura, sob o nome de Cadastro Vitivinícola. Esse cadastro é fundamental para o autoconhecimento do setor e possibilita a sua definição de estratégias, o que é uma carência muito grande da indústria. Hoje, existe esse cadastro no Rio Grande do Sul, mas é carente de informações em relação a outros Estados, o que não oferece o controle das informações desse mercado.

Muitas empresas estão partindo para a verticalização da produção, o que é considerada uma ameaça à ordem social da região, pois muitas famílias obtêm o seu sustento da produção e comercialização de uva para a indústria vinícola. Essa tendência de verticalização da produção é nítida, hoje, na produção de vinhos finos, mas já há indícios que deve se estender também aos vinhos de mesa. Tal fenômeno explica-se pelo fato de que o consumidor irá exigir um aumento na qualidade desse produto sob pena de migrar, como já vem ocorrendo, para o consumo de vinhos finos. Não se acredita que existam estratégias ou parcerias entre as empresas ou com produtores, pois entende-se que cada um trabalha de maneira totalmente individualizada. Foi citado que se tentou coordenar um serviço de logística entre as empresas do Vale dos Vinhedos, localidade de Bento Gonçalves. Tal tentativa não teve êxito, continuando cada vinícola a contratar seu serviço de entrega individualmente. Outra tentativa referida foi fazer centros de distribuição em São Paulo, o que, todavia, travou nos altos custos tributários.

\section{Mudanças nas tecnologias de produção do vinho}

Acredita-se que houve, nos últimos anos, incorporação desse tipo de tecnologia e há dois projetos (um de modernização vitícola e outro de modernização vinícola) que visam a convencer os produtores a alterar as variedades plantadas, com maior custo de produção, que apresentam menos produtividade, mas mais qualidade. Esses programas são estratégicos para a reestruturação do setor. Hoje, $70 \%$ do setor já utiliza essas novas tecnologias de produção.

\section{As TICs na indústria gaúcha do vinho}

No que se refere às tecnologias de informação e comunicação, o entrevistado do Ibravin acredita 
que, como a maioria das vinícolas é de pequeno porte, empresas familiares, com baixo nível de organização e mais voltadas à produção, não usem todas as ferramentas disponibilizadas pelas TICs. Em geral, as empresas do setor carecem de ferramentas básicas, disponíveis pelas TICs, que dão um grande potencial nessa área para o mercado. Contudo, nas empresas maiores se nota um grau elevado de estruturação em TICs.

O Instituto, por meio do Cadastro Vinícola, consegue uma gama de informações sobre a produção e comercialização, em diversos níveis, por vinícola e por municípios. Campanhas de divulgação da marca coletiva Vinhos do Brasil e Wines From Brazil estão ligadas a dois sites na internet, de suporte, que eles consideram uma ferramenta fundamental para atingir os objetivos do projeto. Também por isso, para o Instituto, as TICs são consideradas estratégicas, pela possibilidade de ampla comunicação, além de proporcionarem redução de custos.

A Associação Gaúcha de Vinicultores (Agavi) acredita que a utilização das TICs nas vinícolas é bastante difundida entre seus associados, pelo menos as ferramentas básicas, ainda que mais concentrada na área operacional (nada estratégico e nem mesmo na análise de informações gerenciais). Outro problema é o fato de que a maioria dos empresários do setor vinícola são ex-viticultores e as empresas têm pouca estrutura de gestão e organização. Poucas têm departamentos de vendas, com uma cultura de aguardar os compradores e negociar preço, sem muitas vezes nem ter um estudo do custo daquele produto. Ou seja, a origem e o histórico fizeram com que o setor seja mais voltado para a produção do que para o mercado, o que explica um pouco a crise de estoques. A Agavi pensa em oferecer capacitação para melhoria da gestão das empresas vinícolas.

\section{Resultados da pesquisa por questionários}

Perguntadas sobre o grau de informatização, cinco delas informaram possuir sistema gerencial que abrange toda a empresa, desde a produção até a distribuição final dos produtos. Outras quatro declararam possuir um sistema para operações que abrange mais de uma área da empresa. Uma admitiu utilizar a informática apenas para emissão de notas fiscais e uma não soube responder à pergunta.

Questionadas sobre os itens referentes aos canais de comunicação da empresa, uma não soube
responder.Das dez que responderam, cincoinformaram ter um canal de comunicação interno sistematizado, outras cinco declararam não possuir nenhum sistema. Da mesma maneira, cinco declararam ter algum tipo de sistema de comunicação com fornecedores, e outras cinco disseram não ter nenhum tipo de sistema de comunicação com seus fornecedores.

Dez empresas responderam que possuem sistema de comunicação com clientes. Destas, uma informou ser um desses canais o call center da empresa. Nove informaram que o canal, ou um dos canais, de comunicação com os clientes é o website da empresa. Cinco ainda informaram ter outro tipo de canal de comunicação, além do website ou do call center, e uma declarou ter um sistema de comunicação com seus clientes sem especificar o tipo de canal.

Quanto às perguntas sobre a existência de um departamento de TI na empresa, apenas duas declararam existir esse departamento em sua organização. Uma delas informou que duas das atribuições desse departamento são assistência técnica e participação/ execução estratégica. A outra informou essas duas atribuições, além de considerar como atribuições desse departamento, também, o processamento de dados e a prestação de serviços via internet. Na primeira empresa existe um diretor de TI, enquanto na segunda o cargo mais alto desse departamento é gerencial.

Cinco empresas declararam possuir algum sistema de rastreabilidade da produção, desde a matéria-prima até o produto acabado. Dessas indústrias, uma informou acreditar que esse sistema de rastreamento pode ser percebido pelo distribuidor como um diferencial da empresa ou do produto. Nenhuma das vinícolas declarou disponibilizar as informações de rastreabilidade do produto ao consumidor final. Três responderam não acreditar que o sistema de rastreabilidade possa ser percebido como um diferencial pelo consumidor de seus produtos. As quatro empresas ainda declararam ter outro sistema, além do sistema de rastreabilidade, diretamente com os produtores de uva.

Para três empresas, as TICs não apresentam uma importância estratégica. Dessas, duas responderam que não há nenhum tipo de projeto para promover essa importância. Para quatro empresas, as TICs desempenham um papel estratégico, assinalando-se a importância fundamental na difusão da informação e do conhecimento e, ainda, na comunicação com clientes de forma rápida e com economia nos custos.

Questionadas sobre a existência ou não de um website da empresa, dez responderam afirmativa- 
mente. A respondente que negou a existência do website afirmou que este está em construção. O conteúdo mais utilizado nos websites das vinícolas respondentes é a divulgação de seus produtos (oito casos). A comercialização de produtos online é feita por duas empresas. Duas ainda oferecem serviços ao distribuidor, por meio dos seus sites, e uma oferece serviços online aos fornecedores. Duas empresas, que afirmaram ter website, não informaram o conteúdo que disponibilizam nesse canal.

Uma única vinícola, questionada sobre a forma de distribuição dos seus produtos, afirmou que o faz exclusivamente por meio de distribuidores. Das demais, apenas uma não o faz. Nove empresas fazem distribuição própria, vendendo seus produtos diretamente aos consumidores finais, na própria vinícola, em lojas próprias ou, ainda, pela internet. Dez empresas afirmam fazer a distribuição dos seus produtos utilizando distribuidores, e oito realizam a distribuição diretamente aos restaurantes.

Sete vinícolas discorreram sobre a importância das TICs para auxiliar no desempenho das suas empresas. Foram citados o aprimoramento dos processos, com o uso das ferramentas de informação e comunicação; a disponibilidade de dados para o posicionamento do negócio da empresa; a importância da informação em todos os processos da empresa; o favorecimento da visibilidade e estreitamento da relação com consumidores e produtores, gerando credibilidade e confiança; e a importância fundamental das TICs nos processos de rastreabilidade, no acompanhamento dos produtos e na logística. Ainda, a importância de a empresa estar conectada com rapidez nas informações, o auxílio na melhoria dos produtos e serviços prestados e a importância da divulgação rápida e de baixo custo dos produtos.

\section{Considerações finais}

Por meio da pesquisa bibliográfica foi possível entender a origem que nos traz uma característica importante da indústria gaúcha: o predomínio de diversas e pequenas indústrias produtoras de vinho. Concomitantemente, existem empresas multinacionais, de capital misto, cooperativas de produção e, até mesmo, empresas originalmente familiares que se desenvolveram, se profissionalizaram e que hoje são grandes indústrias, influentes no mercado. O surgimento das cooperativas de produção se deu nos anos
1960, com o incentivo do governo a associações, sindicatos e ao próprio cooperativismo. A etapa seguinte, a partir da década de 1970, foi a instalação de empresas multinacionais. Por fim, a abertura para o mercado externo, na década de 1990, forçou o desenvolvimento das organizações locais, para que ganhassem em competitividade com o produto importado. Esse breve histórico explica a heterogeneidade das empresas pertencentes à indústria, com seus vários níveis de gestão organizacional, estruturação e estratégias para enfrentar os desafios do setor.

Este trabalho confirmou o que Triches (2007) defende, quando caracteriza o ambiente organizacional da cadeia produtiva de vinho do Rio Grande do Sul como em desenvolvimento, mas ainda com diversas deficiências. Entre elas, a falta de conciliação de interesses divergentes e o desafio de se tornar cada vez mais independente do governo, por meio do desenvolvimento e da atuação das principais entidades de classe, das entidades de assistência técnica, de extensão rural, dos centros de pesquisa, dos centros de ensino e das associações dos consumidores.

Puderam ser percebidos alguns pontos de destaque na estruturação da cadeia, como o Ibravin, que congrega os interesses dos três elos da cadeia: produtores de uva, indústria e cooperativas. $\mathrm{O}$ alinhamento de ações, em prol de um mesmo objetivo, é uma das funções do instituto, que surgiu da necessidade justamente de estruturar a cadeia produtiva. O órgão trabalha como braço executivo de uma estratégia do governo para interligação dos elos da cadeia, o Cadastro Vitivinícola, fundamental para que haja informação suficiente para tomada de decisão dos envolvidos. Assim como colocado por Triches (2007), foi reconhecido o implemento de novas tecnologias como forma de aumento na qualidade da uva.

Por outro lado, até como fato gerador da importância dada às associações nos últimos anos, foi observada a falta de ações conjuntas entre as próprias vinícolas. Muitas atividades que são realizadas individualmente poderiam ser feitas em conjunto, com redução de custos e ganho em competitividade, como a questão logística ou mesmo de utilização de equipamentos de produção ociosos. Ou seja, ainda que a região pudesse ser considerada com um cluster, como no caso citado por Porter (1998), na Califórnia, as indústrias brasileiras não utilizam todo o potencial dessa concentração geográfica em seu próprio benefício.

Ainda há dificuldade de profissionalização da gestão das empresas de menor porte. Como origem 
desse problema, tem-se que a maioria dos empresários do setor, antes de o serem, eram viticultores que ascenderam a vinicultores e administram o seu negócio com o conhecimento que adquiriram na prática, o que não vem sendo suficiente para enfrentar as dificuldades atuais.

O segundo objetivo específico foi verificar o nível de utilização atual das TICs na cadeia produtiva do vinho, desde a produção à venda ao consumidor final. Os dados obtidos convergem para as dificuldades de gestão, em geral, das vinícolas, como apontado nas entrevistas. Há problemas operacionais e de gestão, especialmente nas pequenas indústrias, como a dificuldade de apuração de custo de formação de preços. Dessa forma, apesar do potencial apresentado, as associações acreditam que as empresas não utilizam as ferramentas das TICs nem as ferramentas básicas para a gestão. Apesar de haver uso de TICs em processos operacionais, como sistema de emissão de pedidos ou faturamento, não se utilizam essas informações gerencialmente, menos ainda se valendo dessas informações em aplicações estratégicas para o negócio. Enfim, há um uso operacional e pouco gerencial e estratégico das ferramentas disponíveis.

Veja-se que, apesar desse cenário, existem indústrias que estão com sua área de TI bem estruturada, respondendo diretamente ao head da empresa. As TICs proporcionam informação qualificada para a tomada de decisão e a área participa ativamente do processo estratégico da empresa, traz novas ferramentas e possibilidades de uso, na tentativa de ser apenas uma área de apoio e passar a agregar vantagem competitiva. São empresas com sistemas de informação e comunicação desenvolvidos para as suas necessidades, como o caso da que desenvolveu um sistema de rastreabilidade com alto nível de informação, extremamente específico, capaz de identificar todas as matérias-primas e processos pelos quais passou cada garrafa de vinho produzida.

Pôde-se observar, na amostra, a existência de empresas que possuem um sistema para o nível operacional que abrange pelo menos duas de suas áreas. Mais da metade das instituições respondeu que também utiliza um sistema gerencial, abrangendo todas as áreas da empresa, da produção à distribuição do produto final. Todas as instituições que responderam a essa pergunta informaram possuir sistema de comunicação com clientes. Entretanto, poucas informaram ter um departamento especificamente de TI. As atribuições dessa área vão desde o processamento de dados até a participação e execução da estratégia. Cinco empresas declararam possuir um sistema de rastreabilidade, porém, dentre elas, apenas uma acredita que isso possa ser considerado ou sirva como um diferencial na percepção dos clientes. As empresas ainda informaram possuir website, mas, em sua maioria, apenas com a função de divulgação de produtos. Tão somente duas utilizam para comercialização de produtos e apenas duas disponibilizam serviços aos distribuidores e uma para fornecedores.

Pôde-se entender que há uma divergência entre a percepção dos que responderam às entrevistas semiestruturadas e as respostas das vinícolas aos questionários. A maioria das repostas demonstra diversas utilizações das TICs pelas empresas. Contudo, como a amostra foi obtida por meio eletrônico, deve-se alertar que as vinícolas com menor grau de utilização das TICs, que sequer utilizam correio eletrônico, foram excluídas da amostra. De qualquer forma, na amostra, foram obtidas respostas de vinícolas de diversos tamanhos e houve a ocorrência de múltiplas ferramentas de TICs. Para os representantes do setor e de duas grades empresas, não haveria uso pelas empresas, ou seria muito pequeno.

Averiguar a percepção dos produtores quanto ao potencial de agregação de valor do uso das TICs na cadeia do vinho era outro objetivo que se tinha para esta pesquisa. Nas entrevistas com o setor foi possível obter exemplos da importância das TICs na indústria. No Ibravin existem alguns projetos, fundamentalmente dependentes das TICs, para atingir os objetivos propostos para o Instituto. Nesse Instituto, as TICs são consideradas estratégicas, principalmente pela gama de possibilidades de se comunicar amplamente dentro da cadeia e com o mercado consumidor, além de agregar valor e reduzir custos. $\mathrm{Na}$ vinícola na qual foi entrevistado o gerente de TI, foram citados exemplos de redução de custos com comunicação, o incremento na qualidade da informação, com as ferramentas que foram disponibilizadas, que servem para um melhor planejamento desde a produção até a entrega do produto ao cliente. Entretanto, mais uma vez, houve divergência na comparação com as respostas das vinícolas que responderam ao questionário. Para quase um terço dos respondentes, as TICs não apresentam importância na estratégia da empresa. Outro terço disse ter importância estratégica, mas apenas a metade deles conseguiu dar exemplos reais sobre essa importância. O outro terço não quis ou não soube responder a essa 
pergunta. Entretanto, em geral, os respondentes, na maioria gestores das vinícolas, acreditam que as TICs tenham papel importante, como a disponibilidade de dados para posicionamento da empresa, circulação de informação e eficiência dos processos na divulgação dos produtos e nos relacionamentos com fornecedores e consumidores, além da importância para um bom sistema de rastreabilidade e logística.

Portanto, apesar de utilizar diversas ferramentas das TICs e admitir a importância em diversos processos das empresas, poucos entendem que as TICs sejam importantes para a estratégia da empresa. Tal fato pode estar relacionado às dificuldades de gestão e organização, ou seja, ainda que as ferramentas estejam disponíveis, falta organização e planejamento para utilizar as TICs como apoiadoras das estratégias da indústria.

O objetivo seguinte era buscar verificar como o uso das TICs pode diferenciar uma empresa das demais e a produção nacional da produção dos demais países. A bibliografia sugere algumas respostas. Para Porter (2001), existem três aspectos essenciais afetados pela revolução gerada pela tecnologia da informação: a alteração das regras de competição, como consequência da mudança da estrutura setorial; a criação de formas de superar o desempenho da concorrência, gerando vantagem competitiva; e a disseminação de novos negócios, a partir dos existentes.

Para Carvalho e Laurindo (2003), as TICs são vistas como fonte de criação de negócios, de novas formas de relacionamento entre empresas e com o consumidor. As TICs também podem ser vistas como um fator que viabiliza a integração em escala mundial, que estende a competição de mercado a uma nova dimensão. No Rio Grande do Sul, não foram explicitadas formas de como transformar as ferramentas das TICs em um diferencial para a indústria local do vinho, exceto pela de promoção da imagem nacional do vinho nos projetos do Ibravin. No entanto, com base nos aspectos levantados por Porter (2001), contrapondo as dificuldades de enfrentar a concorrência internacional no mercado interno do vinho, puderam ser trabalhadas diversas funcionalidades para que as TICs apoiem as estratégias de aumento da competitividade do vinho nacional. A mais clara é um sistema inter-organizacional envolvendo a estratégia, já em prática, de valorizar as associações e entidades de classe, de modo a organizar os elos do setor para que ganhem em produtividade. Contudo, assim como as opções de utilizar as TICs são infinitas, as possibilidades de apoiar as estratégias de diferenciação das vinícolas são muitas.

Por fim, temos o objetivo de identificar a vantagem competitiva gerada pela utilização das TICs na indústria do vinho. Não foi possível identificar uma vantagem competitiva gerada pela utilização das TICs. Contudo, não se acredita que ela não possa existir, mas apenas que, durante a pesquisa, não foi identificada. É inegável que o principal desafio da indústria nacional, no mercado interno, é ganhar em competitividade para recuperaro espaço perdido para os vinhos importados. Nesse sentido, a própria indústria identificou suas deficiências e já vem trabalhando com ações para revertê-las. São exemplos: a falta de conhecimento nacional e internacional do produto brasileiro e as estratégias de divulgação institucional do produto; a falta de integração das empresas do setor e de alinhamento entre os elos da cadeia produtiva e a criação do Ibravin, para coordenar essa cadeia. Há, ainda, a vantagem competitiva percebida pelas associações, na promoção de ações que beneficiam as empresas em conjunto, pois, isoladamente, não teriam a mesma oportunidade.

Nas vantagens competitivas identificadas na bibliografia, tais como matéria-prima de qualidade superior, relação preço e qualidade e boa identidade própria (TERUCHKIN, 2003), ainda que em nenhuma delas as TICs sejam fontes geradoras podem ser importantíssimas ferramentas de auxílio, mais visivelmente na redução de custos e na criação de uma identidade própria.

Assim, podemos concluir que as TICs, atualmente, não são utilizadas de forma ampla para gerar ou ampliar vantagens competitivas para a indústria do vinho nacional. No entanto, os desafios que se apresentam impõem ao setor um processo de mudanças. Acreditamos ser inevitável que, para a sobrevivência das empresas do setor, estas busquem maior competitividade. Nesse sentido, as TICs devem passar a desempenhar uma função de maior importância, tanto nas relações com os diversos atores envolvidos no processo como nos processos operacionais e nos sistemas de informação de apoio à tomada de decisão.

Se não se conseguiu identificar as TICs como fonte de vantagem competitiva sustentável nas empresas dessa indústria, parece claro que as TICs são de fundamental importância no apoio às estratégias da indústria, assim como podem vir a ser potencializadoras das novas vantagens competitivas a serem geradas. 
Este estudo apresenta limitações. Algumas delas referem-se às dificuldades para a obtenção de respostas, o que reduziu o tamanho da amostra, e outras de acesso a todos os atores envolvidos na cadeia produtiva do vinho. Apesar de remeter a uma realidade, a pesquisa não permite tratamento estatístico dos dados levantados, graças ao tamanho reduzido e à não aleatoriedade da amostra. Devendo ser considerados apenas os aspectos qualitativos, sendo a subjetividade da amostra outra limitação.

A reflexão evidenciada nas entrevistas, e em alguns questionários, mostra não só as dificuldades e necessidades de mudança por parte da indústria vinícola do Rio Grande do Sul, mas também que muitas ações já estão sendo tomadas para corrigir os rumos do setor. O que leva a imaginar o grande campo de estudos, não só exploratórios, para que se conheçam melhor as características da cadeia, mas também que possam oferecer informações e conhecimento e a esse setor produtivo, do qual dependem 20 mil famílias no País.

\section{Referências}

ASSOCIAÇÃO DOS PRODUTORES DE VINHOS FINOS DO VALE DOS VINHEDOS APROVALE. Vale dos Vinhedos tem identidade. Disponível em: <http://www.valedosvinhedos.com.br/ conteudo.asp? $\mathrm{sSecao}=$ aprovale $\& \mathrm{~s} S u b S e c a o=$ indica cao\&sTipo $=$ texto\&sCodTexto $=I P V V \_d i d a t i c o>$. Acesso em: 12 abr. 2008.

BALARINE, O. F. O. Tecnologia da informação como vantagem competitiva. RAE-eletrônica, São Paulo, v. 1, n. 1, p. 67-79, 2002.

BARNEY, J. B. Firm resources and sustained competitive advantage. Journal of Management, New York, v. 17 n. 1, p. 99-120, 1991.

CAVALARI, M. M. A.; CUNHA, M. A. Uso de tecnologias de informação e comunicação como vantagem competitiva em MPMEs em setores tradicionais. 2008. 141 f. Dissertação (Mestrado em Administração) Pontifícia Universidade Católica do Paraná, Curitiba, 2008.

COPET'TI, T. Cinco caminhos para o vinho gaúcho. Zero Hora, Porto Alegre, Caderno Dinheiro, p. 4-5, ago. 2008.

CARR, N. It doesn't matter. Harvard Business Review, London, v. 15, n. 5, p. 243-261, 2003.
CARVALHO, M. M.; LAURINDO, F. J. B. Estratégias para a competitividade. 2. ed. São Paulo: Futura, 2003.

CASTELLS, M. A sociedade em rede. Rio de Janeiro: Paz e Terra, 1999.

CRESWELL, J. W. Research design: qualitative and quantitative approaches. 2nd ed. Thousand Oaks: Sage, 1994.

INSTITUTO BRASILEIRO DO VINHO - IBRAVIN. 2010. Disponível em: <http://www.ibravin.org.br/>. Acesso em: 28 abr. 2010.

KNIGHT, P. T.; FERNANDES, C. C. C.; CUNHA, M. A. V. C. e-Desenvolvimento no Brasil e no mundo: subsídios e programa e-Brasil. São Caetano do Sul: Yendis, 2007.

KNIGHT, P. T.; FERNANDES, C. C. C. (Org.). e-Brasil: um programa para acelerar o desenvolvimento sócioeconômico aproveitando a convergência digital. 2. ed. São Caetano do Sul: Yendis, 2006.

LEVY, P. As tecnologias da inteligência. 2. ed. Rio de Janeiro: Editora 34, 1993.

MAÇADA, A. C. G.; BECKER J. L. Modelo para avaliar o impacto da Tecnologia da Informação (TI) nas variáveis estratégicas dos bancos brasileiros. In: ENCONTRO DA ASSOCIAÇÃONACIONALDE PÓS-GRADUAÇÃO E PESQUISA EM ADMINISTRAÇÃO, 22., 1998, Foz do Iguaçu. Anais... Foz do Iguaçu: ENANPAD, 1998.

MINTZBERG, H. Criando organizações eficazes. 2. ed. São Paulo: Atlas, 2003. In: MINTZBERG, H.; QUINN, J. B. O processo de estratégia. 3. ed. Porto Alegre: Bookman, 2001.

MINTZBERG, H.; AHLSTRAND, B.; LAMPEL, J. Safári de estratégia: um roteiro pela selva do planejamento estratégico. 2. ed. Porto Alegre: Bookman, 2000.

MORGAN, N. A.; VORHIES, D. W.; SCHELEMISCH, B. B. Resource-performance relationships in industrial export ventures: the role of resource inimitability and substitutability. International Marketing Management, New York, v. 35, n. 10, p. 257-272, 2006.

PETERAF, M. A. The cornerstones of competitive advantage: a resource-based view. Strategic Management Journal, New York, v. 14 p. 179-191, 1993.

PORTER, M. How competitive forces shape strategy. Harvard Business Review, London, v. 14, n. 7, p. 78-97, 1979. 
PORTER, M. The contributions of industrial organization to strategic management. The Academy of Management Review, New York, v. 6, n. 4, p. 609-620, 1980.

PORTER, M. Vantagem competitiva: criando e sustentando um desempenho superior. Tradução de Elizabeth M. P. Braga. 2. ed. Rio de Janeiro: Campus, 1989.

PORTER, M. Clusters and the new economics of competition. Harvard Business Review, London, v. 7, n. 6, p. 66-79, 1998.

PORTER, M. Estratégia competitiva: técnicas para análise de indústrias e da concorrência. 2. ed. Rio de Janeiro: Campus, 1999.

PORTER, M. Strategy and internet. Harvard Business Review, London, v. 6, n. 4, p. 278-291, 2001.

SERVIÇO FEDERAL DE PROCESSAMENTO DE DADOS-SERPRO. Especial: o impacto da TI no agronegócio. Disponível em: < http://www.serpro.gov.br/ noticias-antigas/noticias-2004/20040512_04>. Acesso em: 21 maio 2008.

TRICHES, V. Competitividade da cadeia produtiva viti-vinícola do RS. 2007. 161 f. Dissertação (Mestrado em Economia) - Universidade Federal de Santa Catarina, Florianópolis, 2007.

TERUCHKIN, S. R. U. As estratégias empresariais para os vinhos finos no Brasil e no Uruguai: uma análise comparada. 2003. 303 f. Tese (Doutorado em Administração) - Universidade Federal do Rio Grande do Sul, Porto Alegre, 2003.

VILLELA, P. R. de C. O agronegócio na sociedade da informação. In: PROTIL, R. M.; ZAMBALDE, A. L. (Org.). Tecnologia da informação no agronegócio cooperativo. 2. ed. Curitiba: Champagnat, 2003.

WEBSTER, F. Theories of the information society. 2nd ed. London: Routledge, 1995.

WEILL, P.; ROSS, J. W. Governança de TI: como as empresas com melhor desempenho administram os direitos decisórios de TICs na busca por resultados superiores. 2. ed. São Paulo: M. Books do Brasil, 2006.

Recebido: 31/08/2010

Received: 08/31/2010

Aprovado: $13 / 11 / 2010$

Approved: 11/13/2010 